\title{
Editorial
}

\section{International Journal of Prevention and Treatment of Substance Use Disorders - A journal with a difference}

Ravindra Fernando MBBS, MD, FCCP, FCGP, FRCP (London), FRCP (Glasgow), FRCP (Edinburgh), FRCPath (UK), DMJ (London)

Editor-in-Chief (email : ravindrafernando@hotmail.co.uk)

I am indeed privileged to present to you the International Journal of Prevention and Treatment of Substance Use Disorder (IJPTSUD), published by the Colombo Plan Drug Advisory Programme, with collaboration of the National Rehabilitation Center, Abu Dhabi. This is an open access, peerreviewed scientific journal for all professionals interested in the prevention and treatment of substance use disorders.

When the global reports by the United Nations and other organisations show a consistent increasing trend in the use of both illicit and licit substances and the harm they cause, a journal dedicated to the prevention and treatment of substance use disorders is timely.

Morbidity from substance use can be due to their direct physical and mental pharmacological effects, consequences of the methods used to abuse substances and effects of dependence and abstinence. Substance use disorders result in a failure to fulfill obligations at work, school, or home, encountering legal issues and facing persistent or recurrent social or interpersonal problems.

The impact of substance use disorders on health of the victims and their families as well as the community is a major issue. Substance use disorders lead to unproductive employment and increase in crime in the society.

Deaths from substance use are widely reported due to various causes, including infections, such as bronchopneumonia and hepatitis, acute over dosage, inhalation of vomit, acute ulcerative endocarditis and fatal acute pulmonary oedema. Victims of substance use disorders are more prone to accidents and suicide.

The cost to the health services and economy of a country can be significant, although many authorities do not consider this aspect. For example, in the United Kingdom, it is estimated that social and economic cost of substance use is in excess of $£ 20$ billion a year to the economy, in terms of crime, absenteeism and sickness, while the United States estimates it to be around US \$200 billion. 
This journal will consider all the above concerns related to substance use disorders in its future issues. Therefore, I expect the cooperation and contributions of all professionals interested in the prevention and treatment of substance use disorders to make this journal a success. 